\title{
Skin telangiectases and ischaemic disorders in primary aluminium production workers
}

\author{
M ROSSIGNOL, G THÉRIAULT \\ From the School of Occupational Health, McGill University, Montreal, Quebec, Canada
}

Skin telangiectases in primary aluminium production workers were first described in 1976 among Polish workers. ${ }^{1}$ The lesions displayed unique clinical features. They were round non-pruritic red macules whitening on pressure, with sharp edges and ranging in size from 1 to $30 \mathrm{~mm}$. The upper part of the body was chiefly affected: chest, back, shoulders, forearms, neck, and face in order of frequency. Microscopically, they resulted from elastoid degenerescence of connective tissue surrounding the arteriolar, venular, and capillary portion of the peripheric vessels, accompanied by a mononuclear infiltrate. The capillaries were distended and oedematous.

A Russian study showed that the attack rate was significantly higher in electrolysis workers. ${ }^{2}$ In a later study carried out in Quebec the group at risk was narrowed down to workers in the Soderberg electrolysis process, which releases more complex aromatic hydrocarbons in the environment than the newer process (prebake). ${ }^{3}$ After four years of seniority in the Soderberg process, $40 \%$ of the workers had more than 10 skin lesions and after 20 years nearly all were affected.

Skin telangiectases were found to be associated with an excess of ECG abnormalities. ${ }^{4}$ No other association with life style habits or other disease could be identified. The present study, conducted in a large aluminium reduction plant in Quebec, Canada, employing over $6000 \mathrm{men}$, is an attempt to confirm the association between skin telangiectases and ischaemic heart disease. Stroke and arterial insufficiency of the lower extremities (AILE) were also included as ischaemic outcomes.

\section{Method}

The study population consisted of a cohort of men working at a primary aluminium production plant in Quebec who were alive (actively employed or retired) on 11 January 1978 and were free from any of the

Accepted 26 February 1987 three ischaemic diseases studied. In Quebec skin telangiectases are compensated as an occupational disease, on the basis of aesthetic prejudice. Compensated workers were individually matched to three noncompensated workers for date of birth, date of hiring, and seniority at the plant (five year caliper), using the company computerised files.

All men were followed up from 1 January 1978 to 31 December 1983 for the occurrence of an ischaemic event: the company medical records were reviewed for a history of ischaemic heart disease (IHD) (ICD-9 410-414), stroke (ICD-9 430-438), and AILE (ICD-9 $440-448$ ). Only the most severe diagnosis reached by an individual in each of the three diagnostic categories was retained in the analysis. Medical information also included the following covariables: weight and height, blood pressure, cholesterolaemia, glycaemia, smoking and alcohol intake history, and a medical history of lung, thyroid, liver, or kidney diseases or rheumatic fever. The records were of good and equal quality for all men. Death certificates were reviewed for all deaths.

A detailed occupational history was available from the company computerised files. A list of each division, department, and job to which the men had been assigned since the beginning of their employment was obtained for all workers included in the study.

A conditional (to the matched ensembles) logistic regression analysis ${ }^{5}$ was used to control for potential confounders. Odds ratios and confidence intervals were calculated from the regression coefficients using the method described by Schlesselman. ${ }^{6}$

\section{Results}

The study included 126 men compensated for telangiectases $(100 \%$ of eligible compensated men) and 335 non-compensated matched individuals on a predicted total of $378(89 \%)$. The comparison between the two groups shows a great similarity for the covariables (table 1), except for the seniority in the 
Table 1 Comparison of the two study groups for potential confounding variables

\begin{tabular}{|c|c|c|}
\hline & $\begin{array}{l}\text { Workers with } \\
\text { telangiectases } \\
(n=126)\end{array}$ & $\begin{array}{l}\text { Workers without } \\
\text { telangiectases } \\
(n=335)\end{array}$ \\
\hline $\begin{array}{l}\text { Date of birth } \\
\text { Year of hiring at plant } \\
\text { Seniority at plant (years)* } \\
\text { Seniority in Soderberg }\end{array}$ & $\begin{array}{l}\text { Median (range) } \\
1923(1906-50) \\
1943(1933-70) \\
35 \cdot 4(13 \cdot 0-46 \cdot 3)\end{array}$ & $\begin{array}{l}\text { Median (range) } \\
1923(1906-50) \\
1943(1934-70) \\
35 \cdot 3(12 \cdot 6-47 \cdot 9)\end{array}$ \\
\hline \multirow{2}{*}{$\begin{array}{l}\text { Seniority in Soderberg } \\
\text { electrolysis (years)* }\end{array}$} & $32 \cdot 8(0 \cdot 0-44 \cdot 8)$ & $0 \cdot 6(0 \cdot 0-38 \cdot 2)$ \\
\hline & No $(\%)$ & No $(\%)$ \\
\hline $\begin{array}{l}\text { Current smoker } \\
\text { Ex-smoker } \\
\text { Never smoker } \\
\text { Missing }\end{array}$ & $\begin{array}{l}65(53 \cdot 3) \\
50(41 \cdot 0) \\
7(5 \cdot 7) \\
4\end{array}$ & $\begin{array}{l}141(45 \cdot 1) \\
144(46 \cdot 0) \\
28(8 \cdot 9) \\
22\end{array}$ \\
\hline \multirow{3}{*}{$\begin{array}{l}\text { Blood pressure: } \\
\text { Diastolic }<95 \\
\text { Diastolic } \geqslant 95 \text { or } \\
\text { systolic } \geqslant 160\end{array}$} & & \\
\hline & $103(81 \cdot 7)$ & $279(83 \cdot 3)$ \\
\hline & $23(18 \cdot 3)$ & $56(16 \cdot 7)$ \\
\hline \multicolumn{3}{|l|}{ Cholesterolaemia: } \\
\hline $\begin{array}{l}<250 \mathrm{mg} / \mathrm{dl} \\
\geqslant 250 \mathrm{mg} / \mathrm{dl}\end{array}$ & $\begin{array}{l}99(79 \cdot 8) \\
25(20 \cdot 2)\end{array}$ & $\begin{array}{r}256(77 \cdot 3) \\
75(22 \cdot 7)\end{array}$ \\
\hline Missing & $2-$ & 4 - \\
\hline
\end{tabular}

*Seniority calculated to 31 December 1983 or date of retirement or death.

Soderberg electrolysis process for which the median was 32.8 years among telangiectasic men and 0.6 years for the comparison group.

IHD was found in $10.3 \%$ and $12.8 \%$ of men with and without telangiectases respectively, followed by stroke with $1.6 \%$ and $0.9 \%$, and AILE with $4.8 \%$ and $2 \cdot 1 \%$ (table 2). All diagnoses were supported by appropriate evidence whereas diagnosis on the death certificate had been based on the circumstances of death and the medical history. In the IHD category a total of seven deaths, 18 myocardial infarctions, seven coronary insufficiencies, and 24 stable anginas were recorded. One of the seven deaths was a man with telangiectases (rate of $0.8 \%$ ) and the remaining six men without (rate of $1.8 \%)(p=0.39$ Fisher exact test). One death was recorded for stroke (a man with telangiectases) and none for AILE.

Table 2 Number of ischaemic events in the two study groups

\begin{tabular}{|c|c|c|c|c|}
\hline & $\begin{array}{l}\text { Telangiecta } \\
\text { with } \\
\text { No }(\%) \\
(n=126)\end{array}$ & $\begin{array}{l}\text { without } \\
\text { No (\%) } \\
(n=335)\end{array}$ & $O R$ & $p$ \\
\hline $\begin{array}{l}\text { Ischaemic event } \\
\text { Ischaemic heart disease } \\
\text { Stroke } \\
\text { Arterial insufficiency }\end{array}$ & $\begin{array}{c}13(10.3) \\
2(1.6)\end{array}$ & $\begin{array}{c}43(12 \cdot 8) \\
3(0.9)\end{array}$ & $\begin{array}{l}0.61^{*} \\
1.78 \dagger\end{array}$ & $\begin{array}{l}0.13 \\
0.42\end{array}$ \\
\hline of lower extremity & $6(4 \cdot 8)$ & $7(2 \cdot 1)$ & $2 \cdot 34 \dagger$ & 0.11 \\
\hline
\end{tabular}

*OR Adjusted by logistic regression for age, year of hiring, seniority in the plant, seniority in Soderberg electrolysis, smoking, blood pressure, and cholesterolaemia.

†OR Unadjusted; $p$ value obtained by Fischer exact test.
No statistically significant association was observed between skin telangiectases and IHD after controlling for the other variables in the logistic regression analysis $(\mathrm{OR}=0.61,95 \% \mathrm{CI}=0.26-$ 1.46). No confounding effect nor interction could be identified with any of the variables alone or in combination. Owing to the insufficient number of events to perform a logistic regression analysis on stroke and AILE, the crude associations were examined for these diagnostic categories (the absence of a confounding effect in the association between telangiectases and IHD warranted such an approach). No statistically significant association was found for stroke and AILE but a sizable excess of AILE was observed among men with telangiectases $(O R=2 \cdot 34$, $\mathrm{p}=0 \cdot 11)$.

Given the absence of an association, a power calculation was performed on IHD outcome for a one tail test and alpha error of 0.05 . The smallest relative risk detectable with $90 \%$ chance was 1.55 .

\section{Discussion}

The previous findings ${ }^{4}$ of a possible association between skin telangiectases and IHD created a great deal of concern among workers, occupational health professionals and industry. The possibility having been raised, this study was designed to provide convincing evidence, either to support or reject the hypothesis. As it turned out to be the latter, the power of the study was sufficient in that regard.

The largest relative risk observed in this study was due to an excess of AILE in workers with telangiectases $(O R=2 \cdot 3)$. That result was not statistically significant, perhaps because of the small number of events in this diagnostic category (13 cases were found overall). On the other hand, the association between skin telangiectases, a condition that affects predominantly the upper part of the body, and arterial ischaemic disorders of the lower extremities, without any other vascular finding, would be rather puzzling from a pathophysiological point of view.

The finding of no significant association between skin telangiectases and IHD goes against previous observations. ${ }^{24}$ This suggests that skin telangiectases is only a dermatological problem. A bias resulting in a selection of healthier men in the Soderberg process (developing the telangiectases) could explain the seemingly protective effect (not statistically significant) of telangiectases on IHD. This possibility cannot be excluded but would be unlikely to mask an association of clinical significance. The matching for date of birth, date of hiring, and seniority at the plant was intended to minimise such bias by giving men in both groups an equal chance of developing IHD.

As for the aetiology of skin telangiectases, the main 
clue is their characteristic distribution, mainly the upper chest and back. The hypothesis has been raised that these are areas of heavy perspiration and that inhaled environmental contaminant excreted in sweat would be causative. The Soderberg process is associated with the development of skin telangiectases and also with more air pollution, mainly complex aromatic hydrocarbons. The higher degree of air pollution is consistent with the sweat excretion hypothesis.

We thank $M$ Claude Tremblay, the Société d'Electrolyse et de Chimie Alcan Lte, and the Fédération des Syndicats du Secteur de l'Aluminium for their support.

\section{References}

1 Lejman K, Szwarc K, Szydlowski F. Skin lesions in workers of the electrolysis department of the aluminium plant in Skavina Poland. Prezegladu Dermatologicznego 1976;6:117-20. (In Polish.)

2 Sagyka AP, Longunov VP, Selivanenko VG, Kozlenko VV. Relationship between occupational vascular affections of the skin and occupational disorders of the cardiovascular system in workers of the electrolysis plant in the aluminum industry. Vlatnik Dermatol Venerol 1977;7:73-7. (In Russian.)

3 Theriault GP, Cordier S, Harvey R. Skin telangiectases in work ers at an aluminum plant. $N$ Engl $J$ Med 1980;303:1278-81.

4 Theriault GP, Gingras S, Provencher S. Telangiectasia in aluminum workers: a follow up. Br J Ind Med 1984;41:367-72.

5 Breslow NE, Day NE. Statistical methods in cancer research. Lyon: International Agency for research on Cancer, 1980.

6 Schlesselman JJ. Case-control studies. New-York: Oxford University Press, 1982. 